\title{
CARA PELAKSANAAN PEMBERIAN ASI EKSKLUSIF PADA PERAWAT YANG BEKERJA DI RUMAH SAKIT ST. ELISABETH SEMARANG
}

\author{
Priharyanti Wulandari ${ }^{1)}$, Arifianto ${ }^{2)}$, Agnes Risa Mulyaningsih ${ }^{3)}$ \\ STIKES Widya Husada Semarang \\ Email : wulancerank@yahoo.co.id
}

\begin{abstract}
ABSTRAK
Penelitian ini bertujuan untukMendiskripsikan cara pelaksanaan pemberian ASI ekslusif pada perawat yang bekerja di RS St. Elisabeth Semarang. Metode penelitian dalam penelitian ini adalah kualitatif dan jenis penelitiannya adalah desktiptif, sampel penelitian ini berjumlah 5 responden yaitu perawat yang bekerja di RS St. Elisabeth. Pengambilan sampel dengan tehnik Purposive Sampling. Data dikumpulkan melalui wawancara tidak berstruktur dengan tehnik indepth interview Hasil penelitian menunjukkan dua partisipan memberikan ASI secara langsung, Seluruh partisipan dalam bekerja melakukan Pumping hanya 1 kali, seluruh partisipan memperoleh dukungan dari keluarga.Kesimpulan yang diperoleh penulis dalam penelitian ini menunjukkan partisipan mengetahui pengertian dari ASI ekslusif, partisipan dibaantu oleh nenek dan oengasuh dalam pemberian ASI ekslusif, selama berkerja asi disimpan dalam freezer, dukungan keluarga sangat baik dalam pemberian asi ekslusif. Saran yang diberikan oleh penulis dalam penelitian ini adalah diharapkan responden memiliki keinginan yang kuat dalam pelaksaan asi ekslusif, serta menggali lebih dalam pengetahuan tentang pelaksanaan pemberian asi ekslusif.
\end{abstract}

Kata Kunci: Pengetahuan Tentang ASI Ekslusif, Cara Pemberian ASI Ekslusif

\begin{abstract}
ABSTACT
This research is aimedto describe how exclusive breastfeeding is performed on nurses working in St. Hospital. Elisabeth Semarang. The design used in qualitative research and the type of research is descriptive, the sample of this study is 5 respondents in the room magdalena daemen A. Sampling with Purposive Sampling technique. Flavor data through interview is not structured with indepth interview technique.The results showed two participants gave breast milk directly, All participants in the work to do Pumping only 1 time, all participants. Conclusion of this research isParticipants know the notion of exclusive breastfeeding, the participants are assisted by grandmother and oengasuh in exclusive breastfeeding, during the work is stored in the freezer, excellent family support in providing exclusive breast. Suggestion from this research is the respondent has a strong desire in the implementation of exclusive ation, and deeper knowledge about the implementation of exclusive giving.
\end{abstract}

Keywords: Knowledge About Exclusive Breast Milk, Exclusive Breastfeeding Method

\section{PENDAHULUAN}

Keberhasilan pembangunan nasional suatu bangsa ditentukan oleh ketersediaan
Sumber Daya Manusia (SDM) yang berkualitas, yaitu SDM yang memiliki fisik yang tangguh, mental yang kuat dan 
kesehatan yang prima disamping penguasaan terhadap ilmu pengetahuan dan teknologi. Sumber Daya Manusia yang berkualitas merupakan unsur penting dalam keberhasilan Pembangunan Nasional. Anak sebagai sebagai SDM penerus bangsa dan harapan masa depan keluarga, masyarakat dan Negara perlu diberikan pembinaan terarah sedini mungkin, bahkan sejak dalam kandungan. Mencapai tumbuh kembang yang optimal antara lain dengan memberikan ASI kepada bayi sejak lahir, pada menit-menit awal kehidupan sampai 6 bulan. ASI diberikan secara eksklusif tanpa makanan tambaha lainnya, kemudian setelah 6 bulan ASI tetap diberikan dengan didampingi makanan tambahan (Makanan Pendamping ASI) yang disesuaikan dengan usia (KNPP RI, 2008).

ASI merupakan makanan terbaik bagi bayi karena ASI mengandung berbagai zat gizi yang dibutuhkan dalam proses pertumbuhan dan perkembangan bayi. Selama periode sekitar 6 bulan, ASI memiliki unsur-unsur yang memenuhi semua kebutuhan nutrisi yang diperlukan oleh bayi. (Prasetyono, 2009). Pemberian ASI Eksklusif selama 6 bulan telah terbukti baik untuk kesehatan, salah satunya dapat mengurangi tingkat morbiditas bayi yang disebabkan karena infeksi saluran pencernaan. Fakta membuktikan, bahwa pemberian ASI Eksklusif dapat mencegah 13\% kematian balita. Demikian juga dengan Inisiasi Menyusui Dini dapat menyelamatkan $22 \%$ kematian bayi baru lahir/neonatal (DEPKES, 2010).

Angka kejadian dan lama menyusui di seluruh dunia masih saja lebih rendah dari yang diharapkan. Berdasarkan data WHO, cakupan ASI Eksklusif masih rendah untuk negara berkembang dan negara miskin. Cakupan ASI eksklusif di beberapa negara berkembang dan miskin pada tahun 2004, seperti Sub Sahara Afrika sebesar 32\%. Asia Utara 47\%, Afrika Tengah 38\%, dan Afrika Barat $22 \%$. Hal ini menunjukkan hanya $36 \%$ kelahiran bayi di dunia yang mendapat ASI Eksklusif pada tahun 2004. Menurut hasil DEPKES tahun 2010 pada bayi umur 5 bulan, presentase menyusui eksklusif hanya $15 \%$. Dalam profil kesehatan Indonesia tahun 2009, terlihat bahwa cakupan pemberian ASI Eksklusif pada bayi 0-5 bulan di Indonesia menunjukkan penurunan dari $62,2 \%$ di tahun 2007 menjadi 56,2\% di tahun 2008 . Sedangkan cakupan pemberian ASI pada bayi sampai 6 bulan turun dari $28,6 \%$ pada tahun 2007 menjadi $24,3 \%$ pada tahun 2008. Berdasarkan RISKESDA tahun 2015 menyatakan bahwa presentase pemberian ASI Eksklusif pada bayi 0-6 bulan di Jawa Tengah sebesar $61,6 \%$, sedikit meningkat dari tahun 2014 yaitu 60,7\%. Pemberian ASI Eksklusif terendah adalah kota Semarang yaitu $6,72 \%$.

Ada berbagai macam faktor yang mempengaruhi proses menyusui, salah satunya adalah kembali bekerja. Tempat bekerja memberikan kontribusi kepada penurunan angka menyusui wanita bekerja (Murtagh \& Mounton, 2011). Beberapa penelitian memperlihatkan peringkat tiga teratas yang menjadi penghalang pekerja perempuan untuk menyusui saat kembali bekerja. 1. Tidak terdapat fasilitas yang memadai; 2. Malu karena harus membuka payudaranya; 3 . Terjadinya konflik dengan supervisor akibat jadwal yang berubah untuk memerah ASI (Stewart-Glenn, 2008). Data statistik Indonesia menunjukkan terjadi jumlah peningkatan angka tenaga kerja wanita dalam 2 tahun terakhir. Pada tahun 2006 tercatat sekitar 38 juta tenaga kerja wanita terdaftar dan meningkat menjadi 41 juta pada tahun 2007. Pada tahun 2007, jumlah tenaga kerja wanita sebanyak $40 \%$, dengan jumlah peningkatan utama pada wanita usia produktif (Subdirectorate of Statistical Survices and Promotion, 2008).

Beberapa penelitian menyebutkan bahwa status pekerjaan ibu sebagai salah satu penghambat pemberian ASI Eksklusif. Penelitian di Vietnam menunjukkan bahwa ibu yang bekerja memiliki risiko 14 kali lebih besar tidak memberikan ASI Eksklusif (Dearden R. et all, 2007). Penelitian juga telah membuktikan bahwa 
status pekerjaan ibu memiliki efek negative terhadap durasi pemberian ASI. Hal ini membuat ibu bekerja memiliki kesulitan untuk tetap memberikan ASI selama bekerja (Ryan dkk, 2008) Penelitian yang dilakukan di Jakarta oleh Basrowi pada tahun 2012 menunjukkan hanya 32\% perempuan pekerja sector formal dan $20 \%$ perempuan sektor industri yang memberikan ASI Eksklusif.

Dari hasil studi pendahuluan yang dilakukan, rumah sakit St. Elisabeth menyediakan fasilitas untuk pamping susu (ruang Laktasi) bagi karyawan yang sedang menyusui dalam mendukung pemberian ASI Eksklusif. Ruang laktasi berada di lantai 3 poli spesialis yang dilengkapi dengan fasilitas ruangan ber AC, kulkas, alat pompa serta perlengkapannya, ruang tunggu untuk keluarga, perawatan payudara, penyuluhan dan konsul untuk cara memompa ASI dan air minum.

Rumah sakit St. Elisabeth memberikan kebijakan penuh kepada kepala ruang di setiap ruangan untuk mengatur jadwal dinas serta memberikan izin pada perawat untuk meninggalkan ruangngan khususnya perawat yang sedang menyusui diperbolehkan meninggalkan ruangan untuk pamping susu setalah kegiatan di ruangan selesai atau saat jam kerja hampir usai. Peneliti menanyakan kepada salah satu perawat yang memiliki pengalaman pelaksanaan pemberian ASI Eksklusif di ruang Magdalena Daemen A RS St.Elisabeth Semarang mengenai cara pemberian ASI di rumah selama perawat bekerja dan siapa yang memberikan ASI. Dari hasil study pendahuluan tersebut, peneliti memperoleh informasi bahwa selama perawat bekerja, perawat sudah menyediakan ASI dalam botol kaca steril yang disimpan dalam freezer yang kemudian dihangatkan terlebih dahulu sebelum diberikan kepada bayi, dan yang memberikan ASI saat di rumah adalah ibu perawat yang masih tinggal bersama perawat. Peneliti juga menanyakan berapa kali pumping saat bekerja dan bagaimana bila tidak melakukan pumping. Dari hasil study pendahuluan tersebut peneliti memperoleh informasi bahwa perawat tersebut melakukan pumping hanya satu kali saat menjelang akhir sift atau bila kegiatan di ruangan tidak sibuk dan pumping dilakukan di ruang laktasi. Apabila tidak dilakukan pumping, biasanya payudara akan terasa kencang, sedikit nyeri dan terasa tidak nyaman.

\section{METODE PENELITIAN}

Penelitian ini menggunakan metode kualitatif dan jenis penelitiannya adalah deskriptif dengan membedah fenomena tentang gambaran pengalaman pelaksanaan pemberian ASI Eksklusif pada perawat yang bekerja di RS St. Elisabeth Semarang. Penelitian ini menggunakan jenis data primer yaitu data yang didapatkan secara langsung. Selain itu, penelitian ini juga menggunakan data sekunder berupa bukubuku dan jurnal maupun artikel ilmiah. Pengumpulan data dilakukan dengan wawancara secara langsung dengan partisipan dengan menggunakan wawancara tidak berstruktur dengan teknik indepth interview, yaitu suatu teknik wawancara yang berusaha mengetahui lebih mendalam tentang kesulitan, cara, dan gambaran pengalaman pelaksanaan pemberian ASI Eksklusif pada perawat yang bekerja di RS St. Elisabeth. Proses pengambilan data dilakukan dengan mewawancarai perawat yang memiliki pengalaman pelaksanaan pemebrian ASI Eksklusif yang masih bekerja di RS St. Elisabeth Semarang.

\section{HASIL PENELITIAN DAN PEMBAHASAN}

\section{Cara Pelaksanaan Pemberian ASI Eksklusif Pada Perawat Yang Bekerja Di Rumah Sakit St. Elisabeth}

\section{Pengetahuan tentang ASI Eksklusif}

Berdasarkan hasil wawancara kelima partisipan menyatakan bahwa mengetahui secara garis besar mengenai ASI Ekslusif. Hal tersebut sesuai dengan hasil penelitian 
yang dilakukan oleh Nova (2014) yang menyatakan bahwa ada hubungan antara pengetahuan dengan tindakan pemberian ASI Eksklusif, dimana ibu yang memiliki pengetahuan baik lebih banyak memberikan ASI Ekslusif pada bayinya yaitu sebanyak 10 ribu (40 \%) sedangkan ibu yang berpengatuan buruk yang tidak memberikan ASI Eksklusif sebanyak 41 ribu $(87,23 \%)$. Menurut Budiman (2013), factor-faktor yang mempengaruhi pengetahuan antara lain : (1) pendidikan (2) informasi (3) social, budaya dan ekonomi (4) lingkungan (5) pengalaman (6) usia.

Menurut Firmansyah (2012) bahwa pendidikan merupakan penuntun manusia untuk berbuat dan mengsi kehidupan yang dapat digunakan untuk mendapatkan informasi sehingga dapat meningkatkan kualitas kehidupan. Dalam penelitian Rahayu (2007) menyatakan bahwa rendahnya tingkat pengetahuan ibu tentang ASI Eksklusif menyebabkan ibu tidak memberikan ASI Eksklusif kepada anaknya hal ini akan mempengaruhi status gizi ankanya. Penelitian yang dilakukan Elmiyasna (2009) yang merupakan rendahnya pemberian ASI Eksklusif adalah rendahnya pengetahuan ibu tentang ASI Eksklusif, masalah ASI tidak keluar. Selain itu pada ibu yang tidak bekerja tidak tahu bagaimana memberikan ASI perah dan menyimpan ASI perah, faktor lain karena ibu menyusui yang beranggapan ASI tidak cukup diberikan kepada bayi dan bayi tidak akan merasa kenyang.

Hasil wawancara menunjukkan bahwa ASI yang diperah disimpan dalam botol kaca ukuran 100 cc kemudian di simpan dalam frezzer. Menurut Kemenskes RI (2010) ASI yang telah di perah sebaiknya dismpan dalam botol kaca kemudian disimpan dalam frezzer bukan dibagian pintu lemari es, tujuannya adalah agar komposisi ASI tidak rusak. ASI yang disimpan di tempat yang berbeda memiliki perbedaan lamanya ASI dapat bertahan yang dapat dibedakan sebagai berikut : (1) di udara bebas ASI dapat bertahan selama 6-8 jam (2) di lemari es $\left(4^{0} \mathrm{C}\right)$ ASI dapat bertahan 24 jam (3) di lemari pendingin /beku $\left(-18^{0} \mathrm{C}\right)$ Asi dapat bertahan selam 6 bulan (Perinasia, 2009).

\section{Bayi}

Dua dari lima partisipan dibantu oleh pengasuh bayi untuk merawat dan meberikan ASI Eksklusif selama bekerja, sedangkan tiga partisipan meminta nenek untuk merawat dan membantu memberikan ASI Eksklusif selam bekerja. Keluarga maupun pengasuh yang membantu partissipan diajari dan diarahkan untuk merawat bayi terutama dalam memberikan ASI diantaranya yaitu menghangatkan ASI, tempat menyimpan ASI dan cara memberikan ASI yang dihangatkan dengan dot atau sendok agar keluarga dan pengasuh benar-benar dapat membantu partisipan dalam memberikan ASI Eksklusif. Menurut penelitian Sri Rejeki (2008) menyatakan bahwa sumber daya yang membantu memberikan ASI saat ibu bekerja merupakan salah satu kontribusi penting dalam keberhasilan praktik menyusui. Dalam mencapai keberhasil ASI Eksklusif peran nenek yang tinggal bersama dan peran pengasuh juga sangat dibutuhkan terutama bagi ibu yang sedang bekerja. Dengan bantuan nenek serta pengasuh, maka ASI perah yang telah disiapkan untuk bayi selama ibu bekerja dapat diberikan sehingga bayi dapat memperoleh nutrisi serta ASI secara eksklusif.

Hasil wawancara menunjukkan bahwa 4 dari 5 partisipan menyatakan bahwa memberikan ASI kepada bayi dengan menggunakan dot sedangkan 1 partisipan menyuapi dengan sendok. Partisipan lebih memilih menggunakan dot karena takut bayi tersedak atau rongga mulut luka karena terkena sendok. Menurut penelitian yang dilakukan oleh Fitriana (2012) menyatakan bahwa terdapat perbedaan yang signifikan rata-rata jumlah tumpaha antara kelompok pemveri minu dengan menggunakan sendok dan kelompok pemberian minum dengan menggunakan cawa dengan nilai $\mathrm{p}=0,12$ dan $\mathrm{p}=0,05$ yang artinya pemberian minum pada bayi baru lahir menggunakan sendok 
lebih sedikit mengalami tumpah dibandingkan memberi minum dengan cawan. Dari penelitian yang sama juga diperoleh bahwa volume yang diminum menggunakan sendok lebih banyak dibandingkan memberikan minum dengan cawan (Fitriana, 2012). Bentuk sendok dengan ujung yang lebih sempit dibandingkan dengan bentuk cawan yang memiliki mulut lebih lebar, memungkinkan terjadinya sedikit tumpahan saat memberi minum, sehingga volume yang dikonsumsi oleh bayi juga lebih banyak (Riordan \& Wambach, 2010).

Pemberian ASI menggunakan dot tidak dianjurkan karena dapat menyebabkan teknik menghisap yang salah pada bayi dan dapat mengakibatkan bingung puting. Bingung puting ini dapat terjadi jika ibu biasa memberikan ASI lewat payudara, lalu memberikan ASI menggunakan botol, ketika diberikan ASI lewat payudara, kemungkuinan bayi akan menolak karena lebih menyukai menyusu menggunakan botol atau dot. Hal tersebut dapat terjadi karena menyusu lewat dot lebih lancer mengeluarkan ASI disbanding lewat putting payudara. Hal tersebut tidak didukung dari penelitian yang dilakukan oleh Rufaidah (2016) yang menyatakan tidak adanya hubungan antara pemberian ASI Eksklusif menggunakan dot dengan keberhasilan ASI Eksklusif. Hal ini dapat dipengaruhi kerna faktor lain, yaitu adanya dukungan yang baik dari keluarga untuk memberikan ASI secara eksklusif.

Hasil wawancara menunjukkan bahwa lima partisipan memberikan ASI secara langsung kepada bayi tanpa menggunakan dot. Roesli (2009) menyatakan bahwa menyusui bayi secara langsung memiliki manfaat yaitu hubungan psikis antara bayi dan ibu akan menjadi semakin erat karena adanya kontak kulit, kesuburan ibu menjadi berkurang untuk beberapa bulan sehingga menjarangkan kehamilan, serta mengurangi kemungkinan kanker payudara pada masa yang akan datang.

Hasil wawancara diperoleh bahwa 2 dari lima partisipan menyatakan bahwa sebelum memberikan ASI kepada bayi, ASI tidak diturunkan dulu ke lemari pendingin tetapi langsung dihangatkan dengan air panas kemudian diberikan ke bayi, sedangkan tiga partisipan menyatkan bahwa ASI yang akan diberikan ke bayi sehari sebelumnya sudah diturunkan ke lemari pendingin kemudian baru dihangatkan dengan air hangat baru diberi ke bayi. Cara penyimpanan ASI yang telah dilakukan oleh 3 partisipan tersebut sesuai dengangan anjuran Kemenkes RI (2010) namun cara menghangatkannya belum sesuai dengan anjuran dari Kemenkes (2010) yang menyatakan cara menyimpan dan menghangatkan ASI yang telah diperah yaitu : (1) sehari sebelumnya ASI yang beku diturnkan ke lemari pendingin agar proses pelelehan ASI yang beku mencair secara bertahap, (2) ASI dihangatkan dengan air putih suhu ruangan lalu dengan air hangat, (3) aduk ASI dengan cara memutar serta ASI yang sudah dihangatkan tidak dianjurkan untuk didinginkan kembali.

Hasil wawancara menunjukkan bahwa seluruh partisipan memiliki dukungan yang baik dari keluarga terutama orangtua dan suami partisipan. Dukungan dari keluarga akan memberikan timbal balik positif serta kepercayaan partisipan dalam memberikan ASI secara eksklusif. Hal tersebut didukung penelitian yang dilakukan oleh Nuzulia (2013) dimana adanya hubungan antara dukungan keluarga dengan pemberian ASI Eksklusif. Sudiharto (2007) juga berpendapat yang sama, bahwa dukungan keluarga memiliki hubungan dengan suksesnya pemberian ASI Eksklusif kepada bayi. Dukungan keluarga adalah dukungan untuk memotivasi ibu memberikan ASI saja kepada bayinya sampai usia 6 bulan, memberikan dukungan psikologis kepada ibu dan mempersiapkan nutrisi yang seimbang kepada ibu.

Roesli (2007) bependapat bahwa, suami dan keluarga dapat berperan aktif dalam pemberian ASI dengan cara memberikan dukungan emosional atau bantuan praktis lainnya. 


\section{Aktivitas Bekerja}

Hasil wawancara menunjukkan bahwa seluruh partisipan menyatakan bahwa pumping hanya dilakukan 1 kali selama jam dinas atau jam kerja yaitu pada saat jam kerja tidak terlalu sibuk, waktu pumping kurang lebih 45 menit hingga 1 jam. Hal ini dikarenakan rasa tidak nyaman ketika meinggalkan tempat kerja terlalu sering dan lama. Memerah ASI atau pumping biasanya dilakukan oleh ibu yang bekerja, ibu sakit dan tidak dapat langsung menyusui bayinya, ASI keluar berlebihan samapi keluar memancar, dan bayi yang memiliki masalah menghisap (Roesli, 2009). Mensah (2011) dalam risetnya mengungkapkan banyak ibu yang kembali bekerja setelah melahirkan bayi mereka dan harus meninggalkan bayi mereka dirumah. Mereka tidak dapat menyusui bayinya dengan baik seperti yang dipersyaratkan oleh WHO karena kurangnya fasilitas tempat kerja. Dalam hal ini bekerja bukan alasan untuk menghentikan pemberian ASI secara eksklusif selama paling sedikit 4 bulan dan ibu bekerja dianjurkan memberikan ASI perah pada bayinya selama ditinggal ibu bekerja. Mempersiapkan ASI perah selama cuti maupun saat cuti dapat dilakukan. Menurut Roesli (2008) selain bayi tetap memperoleh ASI saat ibunya bekerja juga dapat menghilangkan bendungan ASI, menghilangkan remebesan ASI, juga menjaga kelangsungan persediaan ASI saat ibu sakit atau bekerja.

Waktu pumping yang dilakukan oleh partisipan belum sesuai dengan anjuran dari Kemenkes RI (2010) yang menyatakan bahwa waktu yang tepat untuk memerah ASI ialah minimal setiap 2-3 jam dan tidak menunggu payudara terasa penuh. Akan lebih sulit untuk memerah ASI jika payudara sudah terasa bengkak dan terasa nyeri serta akan menyebabkan penurunan produksi ASI (Kemenkes, 2010). Produksi ASI dirangsang oleh pengosongan payudara dan berlaku prinsip supply and demand yang artinya semakin ASI dikeluarkan maka semakin banyak pula ASI yang diproduksi (Prasetyono, 2009).

Hasil wawancara menunjukkan kelima partisipan menyatakan bahwa jumlah sekali pumping ASI yang keluar bekisar 200-300 cc. Volume pengeluaran ASI pada mingguminggu pertama bayi lahir biasanya banyak, tetapi setelah itu sekitar 450 - $650 \mathrm{ml}$. (Proverawati \& Rahmawati, 2010).Pada ibu yang normal dapat menghasilkan ASI kirakira 550-1000ml setiap hari (Djitowiyono \& Kristiyanasari, 2010). Jumlah ASI yang dibutuhkan oleh bayi tergantung pada usia dan berat badannya (Djitowiyono \& Kristiyanasari, 2010).

Hasil wawancara menunjukkan dua dari lima partsipan menyatakan bahwa salah satu hambatan dalam memberikan ASI Ekaklusif waktu pumping kurang karena setiap 3 atau 4 jam ASI sudah produksi banyak dan merasa payudara sangat penuh dan padat sehingga merasa tidak nyaman. Sebagai ibu yang bekerja, maka waktu luang yang diberikan untuk bayi sangat singkat karena sebagian besar waktunya digunakan untuk bekerja. Minimnya waktu istirahat merupakan salah satu faktor yang menyebabkan waktu untuk pumping menjadi sangat terbatas atau tidak dapat melakukan pumping 2-3 jam sekali.

Hal tersebut sebagaimana dikemukakan oleh Khrist (2011) bahwa bagi ibu yang bekerja kesulitan untuk untuk menyusui bayinya secara eksklusif dikarenakan lebih banyak waktu diluar rumah dan tidak adanya fasilitas khusus untuk memberikan ASI di tempat bekerja sehingga mereka lebih memilih memberikan susu formula sebagai pengganti ASI. Keadaan tersebut menunjukkan bahwa belum dilakukannya Peraturan Bersama Negara Pemberdayaan Perempuan, Menteri Tenaga Kerja dan Transmigrasi, dan Menteri Kesehatan (No.48/Men.PP/XXII/2008, No. PER.27/MEI I/XII/2008 dan No.1177/Menkes/PB/XII/2008) tentang peningkatan pemberian air susu ibu selama waktu kerja di tempat kerja. Dimana ibu-ibu seharusnya memiliki kesempatan untuk 
menyusui atau mengeluarkan ASI untuk bayinya di tempat kerja.

\section{Fasilitas}

Hasil wawancara menunjukkan kelima partisipan menyatakan bahwa tersedianya fasilitas bagi perawat yang sedang menyusui yaitu adanya ruang Laktasi untuk melakukan pumping. Hasil penelitian Budiyanto (2015) menyatakan bahwa tidak ada hubungan antara fasilitas penunjang terhadap keberhasilan pemberian ASI Eksklusif ibu bekerja sebagai tenaga kesehatan di Rumah Sakit PKU Muhammaddiyah Gombong. Berbeda dengan penelitian Yuliarsih (2012) menyatakan bahwa adanya hubungan antara fasilitas dengan pemberian ASI Eksklusif, dimana hasil penelitian menyatakan bahwa tersedianya fasilitas untuk memerah ASI dapat membantu ibu menyusui terutama ibu bekerja dalam menyediakan ASI untuk bayi.

Kementrian Kesehatan telah mengeluarkan Peraturan Nomor 15 Tahun 2013 tentang Tata Cara Penyediaan Fasilitas Khusus Menyusui dan/atau Memerah ASI. Ketersediaan ruang ASI adalah tersedianya ruangan ketika ibu menyusui atau memerah ASI di tempat kerja yang memiliki syarat-syarat khusu dan membuat ibu menyusui merasa nyaman menggunakan ruangan tersebut.

\section{Kebijakan Rumah Sakit}

Hasil wawancara menunjukkan kelima partisipan menyatakan bahwa kepala ruang serta rekan kerja lain memberikan ijin untuk melakukan pumping saat jam kerja, namun belum ada peraturan maupun kebijakan yang nyata dan jelas mengenai waktu yang diberikan kepada perawat yang bekerja untuk melakukan pumping saaat bekerja.

Masih rendahnya target angka capaian pemebrian ASI Eksklusif membuat instansi yang berwenang perlu membuat peraturan yang dapat mendukung ibu bekerja supaya tetap dapat memberikan ASI kepada anaknya. Lingkup nasional telah mengupayakan hak ibu bekerja untuk memberikan ASI kepada ananknya yaitu dengan terbentuknya PP No.33 tahun 2012 tentang ASI Eksklusif,

Pasal 30:

a. Petugas tempat kerja dan penyelenggara tempat sarana umum harus mendukung program ASI Eksklusif.

b. Pengurus tempat kerja dan penyelenggara tempat sara umum harus menyediakan fasilitas khusus untuk menyusui dan/atau memerah ASI seusia dengan kondisi kemampuan perusahaan.

c. Ketentuan lebih lanjut mengenai tata cara penyediaan fasilitas khusus menyusui dan/atau memerah ASI diatur dengan Peraturan Menteri.

Pasal 34:

a. Pengurus tempat kerja wajib memberikan kesempatan kepada ibu yang bekerja untuk memberikan ASI Eksklusif kepada bayi atau memerah ASI selama waktu kerja di Tempat Kerja.

Pasal 35:

a. Pengurus tempat kerja dan penyelenggara tempat sara umum wajib membuat peraturan internal yang mendukung keberhasilan program pemberian ASI Eksklusif.

Peraturan di atas menunjukkan adanya keleluasaan bagi ibu yang bekerja untuk dapat menyusui sehingga anaknya memperoleh ASI Eksklusif.

\section{KESIMPULAN}

1. Partisipan mengenai pengertian ASI Eksklusif, cara penimpanan ASI perah dan pemberian ASI perah.

2. Partisipan dibantu oleh nenek dan pengasuh bayi dalam merawat dan memberikan ASI selama partisipan bekerja, sehingga bayi tetap 
memperoleh ASI meskipun partisipan sedang bekerja.

3. ASI yang telah diperah disimpan dalam botol kaca ukuran $100 \mathrm{cc}$ yang sudah diberi nama, tanggal dan jam, kemudian disimpan di frezzer dapur ruangan ketika masih ditempat kerja. Ketika partisipan sudah pulang, ASI dibawa pulang serta disimpan kembali di frezzer. Ketika memberikan ASI kepada bayi, ASI terlebih dahulu dihangatkan dengan air hangat kemudian diberikan menggunakan dot maupun sendok.

4. Pumping hanya dilakukan satu kali saja selama jam kerja, hal tersebut disebabkan karena rasa tidak nyaman terhadap atasan maupun rekan kerja apabila meninggalkan perkerjaan terlalu sering dan terlalu lama.

5. Dukungan dari keluarga sangat baik. Suami dan keluarga ikut berpartisipasi dengan memberikan support maupun bantuan kecil dalam memberikan ASI.

6. Hambatan dalam memberikan ASI secara esklusif adalah waktu untuk pumping ketika di tempat bekerja dimana belum diberlakukannya waktu pumping untuk ibu menyusui secara nyata.

\section{DAFTAR PUSTAKA}

Amalia , Linda dan Yovsyah. (2009) Pemberian ASI Seegar Pada Bayi Baru Lahir. Jurnal Kesma Nasional. Vol 3, no.4, Februari 2009: 171-175.

Asmijati. (2007). Faktor-Faktor Yang Berhubungan Dengan Pemberian Asi Ekklusif di Wilayah Kerja Puskesmas Tiga Raksa Kecamatan Tiga Raksa Dati II Tangerang Tahun 2007. [Tesis].

Asnani. (2013). Faktor-Faktor Yang Berhubungan dengan Perilaku Pemberian ASI Eksklusif pada Ibu Menyusui.

\section{SARAN}

1. Untuk Rumah Sakit

a. Diberikannya toleransi waktu khusus untuk perawat dalam melaksanakan pumping.

b. Adanya kebijakan atau SPO atau peraturan yang jelas disetiap ruang perawatan mengenai waktu pumping bagi perawat yang sedang menyusui.

2. Untuk Ibu Bekerja

a. Harus memiliki keinginan yang kuat dalam pelaksanaan pemberian ASI Eksklusif serta meminta dukungan dan motivasi serta bantuan dalam pelaksanaan pemeberian ASI Eksklusif.

b. Menggali lebih dalam pengetahuan mengenai pelaksaan pemberian ASI esklusif.

3. Untuk Peneliti Selanjutnya

a. Ada studi kualitatif mengenai motivasi dari tempat kerja terhadap perawat yang sedang menyusui.

Astuti, Ida. (2013). Determinan Pemberian ASI Ekslusif pada Ibu Menyusui. Volume 4, No.1, halaman 1-76

Badan Penelitian dan Pengembangan Kesehatan Kementrian Kesehatan RI. (2013). Penyajian Pokok - Pokok Hasil Riset Kesehatan Dasar 2013. Jakarta: Kemenkes RI.

Basrowi R. (2012). Pemberian ASI Eksklusif pada Perempuan Pekerja Sector Formal. [Tesis] Megister Kedokteran Kerja Fakultas Kedokteran Universitas Indonesia. 
Budiman \& Riyanto. (2013). Kapita Selekta Kuesioner Pengetahuan dan Sikap dalam Penelitian Kesehatan. Jakarta: Salemba Medika.

Budiyanto. (2015). Hubungan Ketersediaan Fasilitas Penunjang Terhadap keberhasilan Pemberian ASI Eksklusif pada Ibu yang Bekerja Sebagai Tenaga Kesehatan. Jurnal Ilmiah Kesehatan Keperawatan, Vol.11, No.1, Februari 2015.

Dearden K.A, Quan Ie N, Do M, Marsh DR, et all. (2007). Work outside the home is the primary barrier to exclusive breastfeeding in rural Vietnam: insights from mothers who exclusively breasfed and worked. Food and Nutrition Bulletin 2002; 23 suppl 4:101-8.

Depkes RI. (2009). Pedoman Pemantauan Wilayah Setempat Kesehatan Ibu dan Anak (PWS-KIA). Jakarta, 2009.

Depkes. (2010). Buku Saku Kesehatan Neonatal Esensial. Kementrian Kesehatan.

Dinkes Provinsi Jawa Tengah. (2015). Profil Kesehatan Provinsi Jawa Tengah Tahun 20015.

Djitowiyono, S., \& Kristiyanasari, W. (2010). Asuhan Keperawatan Neonatus dan Anak. Yogyakarta: Nuha Medika.

Elmiyasna, K. (2009). Kajian ASI Eksklusif Kaitannya dengan Pendidikan dan Pekerjaan Ibu Mneyusui di Puskesmas Nanggalo Padang. Vol.1.No.1 Padang.

Fahrina, Yeye. (2010). Factor-Faktor yang Berhubungan dengan Praktek Pemberian ASI Eksklusif di Wilayah
Kerja Puskesmas UPT Pagarsih Kota Bandung Tahun 2010. [skripsi].

Firmansyah, N. \& Murdani P. (2012). Pengaruh karakteristik (pendidikan, pekerjaan), pengetahuan dan sikap ibu menyusui terhadap pemberian ASI Eksklusif di kabupaten Tuban. Jurnal Biometrika dan kependudukan, volume 1 nomor 1, Agustus 2012:6271.

Fitriana, Lala Budi. (2012). Studi Komparatif Pemberian Minum dengan Cawan dan Sendok Terhadap Efeketifitas Minum Bayi Baru Lahir di RSUP Dr. Soeradji Tirtonegoro Klaten. [Tesis]. Fakultas Ilmu Keperawatan Program Magister Ilmu Keperawatan Universitas Indonesia.

Helmi, Maizu. (2010). Analisis Hubungan Pengetahuan, Sikap, dan Faktor lainnya terhadap Pemberian ASI Eksklusif pada Bayi Usia 6-12 Bulan di Wilayah Kerja Puskesmas W Koto Kinali Pasaman Barat Tahun 2010.

Hidayat, A. (2008). Riset Keperawatan dan Teknik Penulisan Ilmiah. Jakarta: Salemba Medika.

KNPP RI. (2008). Pemberdayaan Perempuan dalam Peningkatan Pemberian ASI. Kementrian Kesehatan RI.

Khrist, G, Josefa. (2011). Faktor-faktor yang mempengaruhi Perilaku Pemberian ASI Eksklusif pada Ibu (Studi Kasus di Wilayah Kerja Puskesmas Manyaran, Kecamatan Semarang Barat). Artikel Penelitian. Semarang: Universitas Dipenegoro.

Kusnanto. (2008). Profesi dan Parktik Keperawatan Profesional. Jakarta: EGC. 
Manuaba dkk. (2009). Memahami Kesehatan Reproduksi Wanita ed 2. Jakarta: Kedokteran EGC.

Marmi, S. (2012). ASI Saja Mama..., Berilah Aku ASI Karena Aku Anak Sapi. Yogyakarta: Pustaka Pelajar.

Mensah, A, O. (2011). The Influence of Workplcae Facilities on Lactating Working Mothers'Job Satisfaction and Oganizational Comintment: A case study of Lactating Working Mathers in Accra, Ghana. (Vol.6, No.7. International Journal of Business and Manajemen).

Meloeng, L.J. (2011). Metode Penelitian Kualitatif. Bandung: PT Remaja Rosdakarya.

Murtagh, L. \& Mouton, Anthony D. (2011). Working Mother, Breast Feeding, and the law. American Journal of Publick Healt, vol 101, no 2.

Mursyida. 2(013). Hubungan Umur Ibu dan Paritas dengan Pemberian ASI Eksklusif pada Bayi Berusia 0-6 bulan di Puskesmas Pembina Palembang. Dipublikasikan untuk Poltekkes Kemenkes Palembang, Jurusan Kebidanan.

Notoatmodjo, S. (2007). Perilaku Kesehatan dan Ilmu Perilaku. Jakarta: PT Rineka Cipta.

Nur Afifah, Diana. (2007). Faktor yang Berperan dalam Kegagalan Praktik Pemberian ASI Eksklusif di Kecamatan Tembalang, Kota Semarang Tahun 2007. [Tesis].

Nur Afifah, Diana. (2007). Faktor yang Berperan dalam Kegagalan Praktik Pemberian ASI Eksklusif. [Skripsi].
Nurdin Usman. (2007). Konteks Implementasi Berbasis Kurikulum. Jakarta: PT Raja Grafindo Persada.

Nursalam. (2013). Konsep Penerapan Metode Penelitian Ilmu Kperawatan. Jakarta: Salemba Medika.

Nurzulia, Fita. (2013). Hubungan antara Dukungan Keluarga dengan Pemberian ASI Eksklusif pada Bayi di Desa Bebengan Kecamatan Boja Kabupaten Kendal. Jurnal Keperawatan Maternitas. Vol.1, No.1. Mei 2013: 1-8.

Pertiwi, Putri. (2012). Gamabaran FaktorFaktor yang Mempengaruhi Pemberian ASI Eksklusif di Kelurahan Kunciran Indah Tengerang.

Prasetyono, Dwi Sunar. (2009). Buku Pintar ASI Eksklusif. Pengalaman, Praktek, dan Kemanfaatannya. Diva Press, Yogyakarta.

Perinasia. (2009). Bahan Bacaan Manajemen Laktasi, Cetakan ke 2, Program Manajemen Laktasi. Jakarta: Perinasia.

Proverawati, A., \& Rahmawati, E. (2010). Kapita Selekta ASI dan Menyusui. Yogyakarta: Nuha Medika.

Rachmaniah, Nova. (2014). Hubungan Tinfgkat Pengetahuan Ibu Tentang ASI Dengan Tindakan ASI Eksklusif. Naskah publikasi. [skripsi]. (Diakses pada 20 Agustus 2017).

Rahayu, Atikah. 2007. Karakteristik Ibu Yang Memberikan ASI Eksklusif Status Gizi Bayi. Jurnal AL Ulum, vol.3 No.3 halaman 8-14.

Rahayu, Mulya. (2013). Gambaran Pola Pemberian ASI Ibu Bekerja Pada Komunitas Pendukung ASI. 
Rasti, Oktara. (2013). Gambaran Pemberian ASI Eksklusif Ibu Bekerja di Desa Serua Indah, Kecamatan Jombang, Tangerang.

Rejeki, Sri. (2008). Pengalaman Menyusui Eksklusif Ibu Bekerja di Wilayah Kendal Jawa Tengah. [skripsi] Fakultas Ilmu Keperwatan dan Kesehatan Universitas Muhammadiyah Semarang.

Riordan, J., \& Wambach, K. (2010). Breasfeeding and Human Lactation. Canada: Jones anda Bartlett Publishers, LLC.

Rufaidah, Ani. (2016). Hubungan Pemberian ASI menggunakan Dot dengan keberhasilan ASI Ekskluasif pada Ibu Menyusui di Posyandu Wilayah Puskesmas Danurejan 1 Yogyakarta.

Kemenkes RI. (2010). Pekan ASI Sedunia. Diakses pada 28 Agustus 2017.

Kementrian Kesehatan. (2012). Peraturan Menteri RI No. 33 Tahun 2012 Tentang Pemberian ASI Eksklusif. Jakarta: Kemenkes RI.

Roesli, U. (2009). Panduan Praktis Menyusui. Jakarta: Pustaka Bunda.

Roesli, U., Yohmi, E. (2009). Manajemen Laktasi. Jakarta: IDAI.

Siregar, D. (2009). Faktor Dukungan Suami Dan Pengetahuan Ibu dengan Proporsi Lama Pemeberian ASI Eksklusif Pada Ibu Bekerja Sebagai Pegawai Negeri Sipil di Beberapa Kantor dan Rumah Sakit Pemerintah di Jakarta. [Skripsi].

Soedjiningsih. ((2007). Seri Gizi Klinik, ASI Petunjuk untuk Tenaga Kesehatan. Jakarta: EGC.
Stewart, R. (2008). Knowledge, Perceptions, and Attitudes of Managers, Coworkers, and Employed Breastfeeding Mothers. AAOHN Journal, Oktober 2008, vol 58, no 10.

Sudiharto. (2007). Asuhan Keperawatan Keluarga dengan Pendekatan Keperwatan Transkultural. Jakarta: EGC.

Sugiyono. (2014). Metode Penelitian Kuantitatif Kualitatif $R \& D$. Bandung: Alfabeta.

Suhartin, Rabaniya. (2011). Gambaran Perilaku dan Faktor-Faktor yang Berhubungan Dengan Pemberian ASI Eksklusif di Kelurahan Kessilape Wilayah Puskesmas Mata Tahun 2011.

Suwignyo, G. (2007). Manajemen Kinerja Pelayanan Rumah Sakit. Jakarta: Sagung Seto.

Undang-undang Republik Indinesia Nomor 38 tahun 2014 Tentang Keperawatan.

Yuliarsih, Desmawati. (2012). Analisis Faktor - Faktor yang Berhubungan Dengan Pemberian ASI Eksklusif pada Ibu Bekerja di RW 08 Kelurahan Bedahan Sawangan Depok 2012. Universitas Pembengunan Nasional Veteran.

Walsh, L. V. (2008). Buku ajar kebidanan komunitas alih bahasa, Handayani Wilda Ika (2 th ed). Jakarta : EGC.

WHO. Breastfeeding, (2009). [Diakses 20 Mei 2017] ; Available from: http://www.who.int/topics/breastfeedi ng/en/.

Wiji, R. N. (2013). ASI dan Pedoman Ibu Menyusui. Yogyakarta: Nuha Medika. 